\title{
The adventure of study: thinking with artifices in a Palestinian experimental university
}

Hans Schildermans, Maarten Simons \& Jan Masschelein

Laboratory for Education \& Society, KU Leuven

\section{ABSTRACT}

The question concerning the relation between thinking and the university is the starting point of this paper. After a very brief outline of some reflections on this topic, the case of Campus in Camps, a Palestinian experimental university, is presented to shed light on this issue. Inspired by Isabelle Stengers' ecology of practices, it is possible to discern four requirements on thinking in the work of Campus in Camps, namely storytelling, comparing, mapping, and using. It will be argued that the particularity of thinking at the university, is that it is done via artifices that initiate processes of composi- tion, problematization, and attention. In the concluding sec- tion, the paper proposes to understand the study practice of Campus in Camps as an adventure that activates a sense of the possible, and hence opens up futures that are different from the ones that present themselves as obvious or unavoidable.

\section{KEYWORDS}

Study practices; requirements; artifices; stengers; campus in camps

\section{Thinking and the university}

The question how to situate thinking within the confines of the institutional infrastructure of the university has been occupying the minds of philosophers since the birth of the modern research university. In The university in ruins, Bill Readings (1996) offers an insight in how Kant and Humboldt conceived of think- ing as a possible bridge between the university on the one hand, and the idea of Reason or Culture, respectively, on the other hand. Readings argues that due to the dominance of the contemporary discourse of excellence, the university has lost such a link towards an idea external to the university. Instead of deploring this so-called dereferentialization of the university, the loss of its societal mission, Readings, however, proposes to seize this opportunity to conceive of the uni- versity as an institution completely committed to Thought. Hence, it is no longer in need of an external referent, be it Reason or Culture, but instead it devotes itself exclusively to thinking.

Next to this, in Medusa's ear, Dawne McCance (2004) presents a deconstructivist reading of foundational texts of the modern university by Kant, Hegel, and Heidegger. Here she shows that these philosophers have situated thinking in the university in such a way that the university was left deaf and dumb. In the end, she turns to the work of Derrida, to introduce an alternative perspective on the question of the relation between thinking and the university in which the university does not close itself off from the animal and the female - a closing off that coincides with the closing off of the institution in the texts of Kant, Hegel, Heidegger but rather opens up its ears to the world. 
Closer to the field of education, there has been the recent publication of The thinking university, edited by Søren Bengtsen and Ron Barnett (Bengtsen and Barnett 2018). The book gathers different authors who try to think about the relation between the university and the world. In the editorial, Barnett and Bengtsen (2018) make clear that their attempt is to situate the university as a thinking institution that gains its spurs through its concern with the world. Their work is presented as a 'collective effort to position the university as a place of thought in the world' (p. 2). Their effort to think the university in relation to the world, instead of celebrating its existence as a thinking institu- tion in and for itself, certainly deserves appreciation. But, it can be argued that their attempt to position the university as a place for thought in the world needs to be resisted.

At this point it is appropriate to be more explicit about two of the premises behind the argument developed in this paper, that will be helpful in shedding a slightly different light on the question concerning the relation between thinking and the university. These premises will be introduced with the aid of two quotes.

Premise I: Think we must. (Woolf 2016, p. 180)

The first quote comes from a letter Virginia Woolf wrote as a reply when she was offered a position at the university. In that letter, these words have a double function. On the one hand, she aims to incite a reflection on whether women should join the ranks of what she called the educated gentlemen of the university. On the other hand, she aims to state that people do not need a university to think since they have always done their thinking, as she calls it, 'from hand to mouth', while conducting their everyday activities in dialogue with others. This premise prevents from perceiving the university as what Stengers (2011b) calls 'the thinking head of humanity' (p. 15). Such a conception positions the university as a thinking university amidst a non-thinking world. It is indeed this understanding of the university that Barnett and Bengtsen risk to the foreground, when conceiving of it as a thinking university in relation to the world, and it is indeed this understanding that needs to be resisted.

Woolf's premise is consistent with Stengers' ecology of practices which will serve as a guiding framework for this paper (Stengers 2005, 2006). Stengers proposes to understand a practice as a specific holding together of require- ments and obligations. Whereas obligations designate what is thought about, requirements make clear how to think according to the rules specific to a particular practice. As such, requirements and obligations are not so much conditions for thought, but rather put constraints on thinking. Endorsing Stengers' ecology of practices means to assume that thinking happens always and everywhere, and hence that there is no necessity for a university that would first have to create conditions for thought to become possible or without which it would be impossible to learn to think. Think we must.

In line with Dewey (1958) and his pragmatic conception of thinking, it is possible to argue that it is more precise to say 'it thinks' rather than 'I think' (p. 232). Thinking, in this view, is like a raging storm that sweeps by and that absorbs everyone and everything it overblows. Thinking is not an activity to be done on behalf of an intentional subject that chooses to think, it is rather what one gets caught up in, like one gets caught up in a storm. What is at stake is not to play with thoughts, but rather to be put at play by thinking. What needs further clarification is how practices, or more precisely study practices, tame the whims and fancies of capri- cious thinking by steering thought in the direction of obligations and submitting it to requirements. 
Premise II: It matters what matters we use to think other matters with; it matters what stories we tell to tell other stories with; it matters what knots knot knots, what thoughts think thoughts, what descriptions describe descriptions, what ties tie ties. It matters what stories make worlds, what worlds make stories. (Haraway 2016, p. 12)

The second quote underscores the fact that it matters what university we study to study the university with. It urges to think in relation to specific practices instead of in relation to general rules or norms.

Faithful to the second premise, the remainder of the paper will analyze the specific requirements for thinking as they come to the fore in the study practices of the Palestinian experimental university Campus in Camps. Campus in Camps is a small-scale grass roots educational initiative that addresses the need of the camp inhabitants to come up with different repre- sentations of the Palestinian refugee and the camp beyond the default positions of victimization ('the camp is an extreme form of violence that should be stopped') and normalization ('the camp exists already for 70 years and its conditions have become normal since water, electricity, etc., is available').

In doing so, participants study the right of return, the claim to go back to the original houses from before the Nakba, in relation to the actual camp conditions. Critical about the proliferation and specific operativity of non- governmental organizations (NGOs) in the refugee camps, the initiators pro- posed to understand their practice as a university, instead of an aid organiza- tion. Together with the inhabitants of Dheisheh Refugee Camp and students from Al-Quds Bard University, the participants of Campus in Camps inquire the conditions they live in, in view of possible social and spatial transformations in the camp. As such, it is an interesting university to study the university with.

Elsewhere, it has been argued that life in exile is what the participants as practitioners think about - the obligation of their practice -, viz. what makes them hesitate not to be too quick to victimize or normalize their status as refugees, but rather makes them 'stay with the trouble' (cf. Haraway 2016), and think through what is happening and act accordingly via specific social and spatial interventions. The aim of this article is to shed light on the four requirements - next to obligations the key element in Stengers' conceptualization of practice - for the thinking that the study practice of Campus in Camps imposes on its participants.

\section{Four requirements for thinking}

\section{Storytelling}

The first requirement is the requirement to write stories. All publications contained in The Collective Dictionary testify to this requirement. This dictionary aimed to elaborate concepts that were deemed indispensable when thinking about the inhabitants' life in the camp, such as participation, ownership, and well-being. Here, the focus will be narrowed down to the booklet Knowledge. However, in this publication, the reader will not find any coherent theory of the concept of knowledge. The contributions rather take the shape of stories that bring together and reflect on experiences participants have underwent and that they deem relevant in order to think about knowledge. Gropingly, these contributions articu- late aspects of the notion of knowledge based on the everyday experiences of the participants. As such, 
the aim of the publication is to gather people around the concept of knowledge in order to bring together different perspectives and stand- points vis-à-vis this issue. These different takes on the question of knowledge are brought to the fore in the form of stories. This grants the possibility to contrast textbook definitions of knowledge with stories about everyday experiences.

In We are the ones who build our knowledge, one of the stories in the booklet, two participants fabulate that it is impossible to think knowledge as either theoretical or practical but that it needs to be thought of as an action. Moreover, an action that is shared and, hence, through which knowledge is shared. They ground their argu- ment in the experiences they had during a project in the course of which they interviewed different women on their educational background. They found that almost none of them held an academic certificate but were nevertheless very knowledgeable about many things - the examples given include for instance sewing and designing clothes. This kind of knowledge, which is to be found in specific skills and activities, remains however often barely recognized as a valuable source of knowledge. The participants argue that it is hard or even impossible to confine knowledge in certificates and degrees that make it into an individual property. They fabulate a conception of knowledge as collective action in which also other persons can participate. Initiated, and hence partaking in a specific shared experience - of sewing, of cooking, of speaking a foreign language -, knowledge can be shared. As such, knowledge cannot be appropriated by individuals and commo- dified by means of degrees and certificates. On the contrary, it needs to be understood as embedded in concrete actions that can be performed collectively (AlTurshan and Hamouz 2013). Fabulating a concept of knowledge means, in this case, to embed it within the concrete activities in which it is used and shared.

As such, The Collective Dictionary can be understood as a way of overcoming what Whitehead (1938) has called 'The Fallacy of the Perfect Dictionary' (p. 235). This term indicates the belief that we know and have coined all the fundamental ideas that can be applied to our experience, and that these ideas can be explicitly expressed in human language. In order to omit The Fallacy of the Perfect Dictionary and inspired by what science fiction writer Ursula K. Le Guin calls The Carrier Bag Theory of Fiction, it is proposed to think about The Collective Dictionary as a carrier bag of concepts for living together in the camp. Stories, according to Le Guin, are carrier bags that are used for collecting, carrying, and telling the stuff of living. Containing not only wild facts and messy descriptions but also remote memories and high hopes, it is often said of stories that they blind us for the present. However, instead of seeing storytelling as deceit and disguise Le Guin (1989a) asks to understand the story as 'an active encounter with the environment by means of posing options and alternatives, and an enlargement of present reality by connecting it to the unverifiable past and the unpredictable future' (pp. 44-45).

To summarize, the first requirement of study practices in Campus in Camps is that it is needed to tell stories. This allows for relating abstract concepts to everyday experiences. Storytelling situates concepts inside the events, experi- ences, and relations that make up the fabric of the concept. Stories make us think about the way a specific concept can be used to explain or justify a situation or they can lure our feelings towards other ways of experiencing an event.

\section{Comparing}


The second requirement for study practices is the requirement to make compar- isons. The aim of the projects Common1 and The Municipality, belonging to The Collective Dictionary and The Initiatives respectively, was to compare the city of Doha with the camp of Dheisheh. Doha and Dheisheh are divided from another by just one street and are as such part of the same agglomeration. This raises the question what it means to move from the camp to the city as a refugee. The two publications make use of interviews and photographs in order to construct a rapport between Dheisheh and Doha. In opposition to the notion of relation which has become a commonplace in social theory, the notion of rapport under-scores the fact that the relation is not always already there but that it can be and needs to be constructed (Stengers 2011a). Moreover, it makes explicit the work that has to be done in order to create a relation; or, in the case, of the requirement to make a comparison.

In Visual investigation Dheisheh/Doha, an attempt is made to make a comparison between the camp and the city by contrasting pictures. What is striking to see when looking at these pictures is the difference between Dheisheh and Doha. The pictures of Dheisheh give the impression of a crowded, disorderly, dirty, overgrown town, cluttered with informal dwell- ings heaped up next to small alleys. Doha, on the contrary, is represented as an empty, orderly, tidy settlement, that seems to be constructed according to a strict and fixed housing scheme with big lanes and where public and private domains are nicely separated. The aim of the series is not to compare Dheisheh and Doha from the point of view of a normal or ideal city, but just to draw out the differences between the two. The pictures do not seduce the beholder to judge one of the cities from the point of view of the other. Neither the left, nor the right side of the photograph seem appealing, in the sense that the beholder would be inclined to make clear his preference where to live. Both sides convey an uncanny feeling which allows the beholder to retain some distance towards both the camp and the city.

A rapport has been created between a camp and a city that made the participants think about the always-already-there relation between Dheisheh and Doha. As such, not only can it be claimed that the rapport made a comparison possible, but also, and more importantly, that the comparison made a rapport possible. The comparison allowed for rethinking and recreating, on the one hand, the relationship between the camp and the city, and on the other hand, the relationship between the Dheisheh/Doha agglomeration and its inhabitants on both sides of the border that separates the camp from the city. In short, the construction of a rapport between Dheisheh and Doha in the form of a comparison allowed for creating a rapport between the issue of the relation between camp and city on the one hand and the thinking public that gathered around this issue - made present via the photographs - on the other hand.

Drawing out the divergence between the city and the camp, each in its own particularity, with full force and without foul play, granted the possibility to get a sense of where and how the two intermingle, for instance in the debates on what it means to live as a refugee in Doha instead of Dheisheh. Besides, in this publication, we find an image that imitates the style of the first pictures of the series. It is a wide shot of both Dheisheh and Doha on opposite sides of the street. Below is indicated that on the left-hand side is Doha, whereas on the right-hand side we see Dheisheh. However, in contrast to the first pictures, this image does not allow for making a clear distinction between the camp and the city based on the picture alone. The beholder needs the additional information that is given below in order to discern the two, and even then, each side of the street seems to mirror the other. The contradiction between camp and city evoked in the initial comparison was transformed into a contrast. This means that both sides of the street - camp and city - are no longer just opposed to one another, but 
that the participants have gained a perspective in which the question of a refugee identity emerges as a point of convergence between the two. The comparison required to attend to the specific ways in which camp and city diverge, but also to the tactical alliances around the question of a refugee identity that come into being between the inhabitants of the camp and those of the city.

\section{Mapping}

As a third requirement, students need to make maps. In the process of mapping, elements from the environment are retained, selected and ultimately assembled on a two-dimensional plane. In The Unbuilt, the participants have made a map of Dheisheh, in order to get an overview of the different empty spaces in the camp. Their concern was what one of the participants has called 'the forum of the camp'. This term is defined as 'the place in which people used to talk, to plan, to demonstrate, and to organize social and political practices freely and without being restricted by a certain vision or agenda but rather the vision that they decided to adapt' (Abu Aker et al. 2013, p. 22). The investigations conducted in the course of this activity were aimed at surveying potential sites for recreating such a forum. The unbuilt plots that were found were photographed and, together with the map, they constitute the materials of this publication.

It can be argued that in the process of mapping and photographing the camp, different meanings of the notion of the word milieu - environment, middle, medium, and passage entangle. It is by drawing a map and taking pictures of Dheisheh that the camp as an environment is visualized and that it becomes something that the participants can start beholding. In other words, it can be claimed that the camp as an environment becomes a middle around which people gather. As such, the camp is a milieu in a double sense. On the one hand, it is the environment in which people live from day to day. On the other hand, it is the middle that brings people together and that makes them ask questions about the future of the camp. In this case, the discussion revolves around the question how a forum of the camp can be created by means of the regeneration of empty spaces. Besides, the third meaning of milieu, namely medium, can be discerned in the activity of map-making. The map as medium indeed allows the participants to gather around an issue of concern - what they have called the forum of the camp - in a way that they make the camp present in their conversation. The map makes it possible not only to discuss about the camp, but it makes the camp-as-map a participant in the discussion. It becomes something to think with. At this point, the fourth understanding of the milieu comes in. The notion milieu denotes not only the environment that surrounds us, the middle that we can attend to, and the medium that affords us the capacity to perceive and act. It is also a place of passage, of indeterminacy and hence of present-oriented possibility. It is the place where past and future grope together and entangle, a passage point where the direction is still unknown and topic of debate.

It is possible to conceive of the social space of the map as a place where it is possible to think about the future of the camp with the camp, made present as map. In this case, it granted the possibility to discern possibilities for reinstal- ling a place to discuss and debate within the infrastructure of Dheisheh. Moreover, the practice of mapping made it possible to raise the question what it means to create such a place within a refugee camp. It allows for slowing down around the camp as map, as a middle around which people gather in their discussion about the creation of a future forum of the camp. To situate this map among the 
other entities underscores the fact that the map does not allow to reach a point outside the camp, an Archimedean point that due to its exteriority would allow to pass judgement. The fact that the map is 'among' other entities requires to understand it as a new knot in the meshwork of the camp (cf. Ingold 2011). It is here, in the transformation of the milieu as environment into the milieu as middle - a new knot in the meshwork - that it is possible to discern this fourth understanding of milieu, viz. the milieu as a site of possibility and indetermination.

\section{Using}

The fourth and last requirement for study practices in Campus in Camps is the requirement to use. In this context, use should not be understood in the ordinary consumerist sense, however, but rather as activating the question which processes of subjectification are at work while using. In this section, the investigations conducted during the preparations for the publication of The Square are taken as a starting point to think about practices of use and the possibility of common use. In the context of this initiative, the participants tried to think about the meaning of public space within a camp in relation to the public square that was constructed in the camp of Fawwar, in 2007. Fawwar has the reputation of being a rather conservative camp in which women are often assigned the role of staying at home and taking care of the household. Hence, most of the women were very sceptical about the establishment of the square when the United Nations Relief and Works Agency (UNRWA) came up with this idea. The women argued that they would have no right to the square because women did not feel authorized to be present in public spaces. The experience that an external authority (viz. UNRWA) cannot make a public space via the construction of a square instigated a learning process around the question what it means that a space is public: How does the presence of the square normalize or legitimize the camp? How can such a place be used in order for it not just to be a place that is 'made free' by an external authority, but taken in hands as a commons by a community of people who henceforth become commoners? Via an action approach, they experimented with different ways of using this space. The challenge was to find a way of gathering in this open space that was until then public in principle, but in practice barely ever used.

After a discussion in the Women's Center that helped to articulate the unease the women felt in relation to the square, they decided to research which new uses would be possible by means of using the square, instead of taking the feeling of exclusion as a critical point from which it is possible to denounce the publicness of the square. Concerned with the possibility of a shared use of the space, and vigilant about an understanding of public as 'for anyone' (after all, from previous experiences they had learned that they were practically excluded from such an 'anyone'), they experimented with different activities (e.g. cleaning, cooking, learning English) that allowed for reclaiming the square, and for partially appropriating it through use. Stengers (2012) explains that:

The culture of uses, and not the uses justified by a diagnosis or by aiming at an end, is a problem of collective interest, which requires a collective knowledge. This can be called a collective expertise in the old sense where the expertise referred first of all to knowledge derived from experience and cultivated in its relationship with experience. (p. 199, Author's Translation) 
In relation to cultures of use, Stengers underscores two aspects. In the first place, she stresses collectives. She does not refer to individuals that acquire insight in how something can be used, but to collectives that produce knowl- edge in relation to the ambiguous force around which they gather. In this case, it concerns a square that risks to normalize the camp due to the presence of public space. Secondly, this knowledge is experiential. It cannot be derived from a general rule or a faraway objective but should be related to experiences of use. This requires an experimental investigation of how this force can be used.

In that sense, the use of the square can be called generative (cf. Gutwirth and Stengers 2016). It generates new relationships between the people and the square, new activities that can be performed there (such as learning English), and new social bonds between the people that have gathered. The use of the square as commons allows for the coming into being of new relationships between people and the square, as well as for the emergence of a sense of belonging. The process does not extract the potential of the square to the full, neither does it exclude other possible uses. Instead, it actualizes the space in a way that it is no longer public in the sense of commissioned by an external authority, 'for anyone', but rather that it is made public that the use of the square gathers a public.

In short, a threefold generativity discloses itself in the course of the process of use. Use is first and foremost generative of what is being used. At first sight, this might sound counterintuitive as the use is often conceived of as extractive. But, what Gutwirth and Stengers mean is that use does not necessarily entail extraction, but that it can also foster care. Cleaning the square allowed the participants to gain a sense of belonging to it. It is by cleaning, by taking care, that they made the plaza into a common. Secondly, use is generative of the community that uses. It is by using that the participants got used to the square and that they became capable of making common use of it. Finally, use is generative of the terms of use by which the association of users makes use of what is being used. Such terms of use, however, can never be formulated in general, for once and for all, but are subject to continuous careful reconsideration.

\section{Thinking with artifices}

In the previous section, four requirements for thinking have been outlined that the study practices of Campus in Camps demand from the participants. These requirements aim at slowing down thinking, avoiding hasty conclu- sions, and making the participants hesitate, turning them into students. These requirements allowed for generating a way of thinking about the camp that refrained from foregrounding either its exceptionality or its possible normalization. Instead, the participants discussed what life in exile could mean for them, developed a language to come to terms with their experiences, and engaged in initiatives that tried to bring about social and spatial interventions in the camp. In order to think according to the require- ments of the study practices of Campus in Camps, it was necessary for the participants to tell stories, to make comparisons, to create maps, to make use. In short, and referring to Stengers (2017), it can be argued that they were required to think with artifices. This means to activate and generate processes of assembly, of bringing people together around an issue that becomes a matter of study, something that they do not merely discuss about, but actively inquire in relation to the question how this issue affects their lives. 
The efficacy of the artifice is to force divergent reasons, concerning the problem of the right of return in this case, to be expressed in a relation to the artifice that gives this problem the chance to pose itself on its own terms, as opposed to the politicized renderings of it in terms of exceptionality or normality. As such, the artifice instigates three interdependent processes, viz. composition, problematization, and attention.

The first process, of composition, has to do with the way in which people are brought together around something (e.g. a map, a square). It fosters a mutual sensibility and readiness to be affected by a question. It brings people together in a way that undoes both personal intentions and general solutions, in order to make them susceptible for the reasons that the issue at hand will require itself (as opposed to personal or general reasons). For instance, in the case of the square, gathering in this place and making use of it allowed the participants to become affected in a different way by the question that it posed, namely no longer in terms of exclusion ('public spaces are inaccessible for women') or normalization ('the presence of public space proves that the camp has developed into a regular living environment'), but rather in the sense that they started to think what kind of uses could be considered as common use and what this means in relation to the camp. Using suspends personal objections ('I do not feel at ease in public space') as well as general solutions ('camps need public spaces for informal gatherings'), and makes it possible to study what it means to come together in public space within a camp.

This relates to the second process, of problematization, which indicates the way in which an issue that plays on a general level - the right of return - emerges in very concrete situations (e.g. the relation between the camp and the city, the presence of public space). Storytelling, comparing, mapping, and using are material and technical ways that foster the problematization of the camp condition and the right of return. It is about deploying very specific study techniques (e.g. taking pictures, making maps) in order to generate study materials around which they can gather and in the presence of which have their discussions. The presence of study materials drastically changes the nature of the discussion. It is no longer, as argued in the section on composi- tion, about giving personal or general reasons, but about having one's reasons being put at risk by the study materials. This means that the participants never merely discuss about the camp, but rather that they discuss with the camp as it has been made present via, for instance, stories and maps. It turns the camp itself into a participant in the discussion about the right of return and gives it the power to object to the reasons the other participants in this discussion might give.

The third and last process instigated by the artifice is attention. Due to the presence of pictures, stories, maps, etc., participants become more hesitant with regards to their opinions concerning the camp and the related issue of the right of return. By paying attention to the particularities of the camp condition as well as the lived experience of life in exile that they have scrutinized during fieldwork exercises, seminars, etc., it becomes possible to shed a different light on the camp and to come up with more precise and more powerful representations of what it means to be a refugee and to live in a camp that exists already for more than 70 years. The artifice allows for paying attention to the particularities of a problematic situation because it 'compli- cates the process, slows it down, welcomes all doubts and objections, and even actively incites them, while also transforming them and listening in a different mode' (Stengers and Bordeleau 2011, p. 27). It is at that point that processes of composition, problematization and attention mutually rein- force each other in the course of a collective adventure of study. 


\section{The adventure of study}

In a reflection on the work of Campus in Camps, the anthropologist Ilana Feldman, who has given a few workshops there, argues that the achievement of this initiative is to articulate a vision of return that is future, rather than past oriented and that is collective rather than individual. This is a vision not just about the reclamation of private lands and houses, but of the future availability of the collective space of Palestine - the sea, the commons. And it relies not just on the recognition or granting of that right by formal bodies, but on the efforts of people to find ways (small though they may be) to enact it. (Feldman 2016, pp. 425-426)

She explains that the program engaged its participants in a serious collective thinking process on the right of return, an adventure in the Stengersian sense that transformed the terms in which this right of return was understood.

Storytelling, comparing, mapping and using made it possible to slow down the process of question and answer in order for the participants 'not just to express what they were thinking anyway but to feel their thought becoming part of the collective adventure' (Stengers 2002, p. 252). Processes of composi- tion, problematization, and attention instigated by the artifices initiate such an adventure of study, an adventure that opens up other futures than the ones that present themselves as obvious or unavoidable (viz. victimization and normalization) but activate a sense of the possible.

As such, every adventure of study is an adventure of hope. Stengers explains that hope marks the difference between probability and possibility:

If we follow probability there is no hope, just a calculated anticipation authorized by the world as it is. But to think is to create possibility against probability. It doesn't mean hope for one or another thing or as a calculated attitude, but to try and feel and put into words a possibility for becoming. (Ibid., p. 245)

In that sense, it is possible to argue that Campus in Camps enacts an adventure of study that it is not about making political claims, but rather inquiring the participants' living conditions via study practices that artifactualize the process of thinking and that hence gives the camp the power to turn them into students.

\section{References}

Abu Aker, Q., I. Al-Barbary, A. Al-Laham, and A. Al-Saifi 2013. "The Unbuilt. Regenerating Spaces." Accessed http://www.campusincamps.ps/wp-content/uploads/2013/07/TheUnbuilt_web.pdf

Al-Turshan, A., and N. Hamouz. 2013. "We Are the Ones Who Build Our Knowledge." In Knowledge, edited by Q. Abu Aker, N. Hamouz, B. Al-Jaffari, A. Al-Laham, and A. Al- Turshan, 16-21. Accessed http://www.campusincamps.ps/wp-content/uploads/2013/02/ knowledge.pdf 
Barnett, R., and S. Bengtsen. 2018. "Introduction: Considering the Thinking University." In The Thinking University. A Philosophical Examination of Thought and Higher Education, edited by S. Bengtsen \& R. Barnett, 1-12. Dordrecht: Springer.

Bengtsen, S., and R. Barnett, Eds. 2018. The Thinking University. A Philosophical Examination of Thought and Higher Education. Dordrecht: Springer.

Dewey, J. 1958. Experience and Nature. New York (NY): Dover Publications.

Elzenbaumer, B. 2018. "Speculating with Care: Learning from an Experimental Educational Program in the West Bank." Architectural Theory Review 22 (1): 100-119. doi:10.1080/ 13264826.2018.1412330.

Feldman, I. 2016. "Reaction, Experimentation, and Refusal: Palestinian Refugees Confront the Future." History and Anthropology 27 (4): 411-429. doi:10.1080/02757206.2016.1201482.

Gutwirth, S., and I. Stengers. 2016. "Le droit à l'épreuve de la résurgence des commons." Revue Juridique de l'Environnement 41 (2): 306-343.

Haraway, D. 2016. Staying with the Trouble. Making Kin in the Chthulucene. Durham, NC: Duke University Press.

Ingold, T. 2011. Being Alive. Essays on Movement, Knowledge, and Description. London: Routledge.

Le Guin, U. K. 1989. "Some Thoughts on Narrative." In Dancing at the Edge of the World. Thoughts on Words, Women, Places, edited by U.K. Le Guin, 37-45. New York, NY: Grove Press.

McCance, D. 2004. Medusa's ear. University foundations from Kant to Chora L. New York, NY: SUNY Press.

Petti, A. 2013. "Campus in Camps. A University in Exile." Accessed https://issuu.com/campu sincamps/docs/the_cic_book-pages

Petti, A. 2018. "Campus in Camps. Knowledge Production and Urban Interventions in Refugee Camps." In The Routledge Companion to Planning in the Global South, edited by G. Bhan, S. Srinivas, and V. Watson, 334-344. London: Routledge.

Readings, B. 1996. The University in Ruins. Cambridge, MA: Harvard University Press.

Stengers, I. 2002. “A 'Cosmo-Politics': Risk, Hope, Change.” In Hope. New Philosophies for Change, edited by M. Zournazi, 244-273. Annandale: Pluto Press.

Stengers, I. 2005. "Introductory Notes on an Ecology of Practices." Cultural Studies Review 11 (1): 183-196. doi:10.5130/csr.v11i1.3459. 
Stengers, I. 2006. La Vierge Et Le Neutrino. Les Scientifiques Dans La Tourmente [The Virgin and the Neutrino. Scientists in Turmoil]. Paris: Les Empêcheurs de penser en rond.

Stengers, I. 2011a. "Comparison as a Matter of Concern." Common Knowledge 17 (1): 48-63. doi:10.1215/0961754X-2010-035.

Stengers, I. 2011b. Thinking with Whitehead. A Free and Wild Creation of Concepts. (M. Chase, Trans.). Cambridge, MA: Harvard University Press.

Stengers, I. 2012. “Usagers: Lobbies ou création politique?" In Médecins et sorciers, edited by T. Nathan and I. Stengers, 175-205. 3rd ed. Paris: Les Empêcheurs de penser en rond.

Stengers, I. 2017. Civiliser La Modernité? Whitehead Et Les Ruminations Du Sens Commun [Civilizing Modernity? Whitehead and the Ruminations of Common Sense]. Dijon: Les presses du réel.

Stengers, I., and E. Bordeleau. 2011. "The Care of the Possible." Scapegoat: Architecture/ Landscape/Political Economy, no. 1: 12-27.

Whitehead, A. N. 1938. Modes of Thought. New York, NY: Free Press.

Woolf, V. 2016. A Room of One's Own and Three Guineas. London: Vintage Classics. 